УДК 669.712.1.002.68

\title{
Prospects for the Introduction of Technology Ultra-Dry Storage of Red Mud
}

\author{
Sergey N. Gorbachev*a, \\ Aleksandr V. Alexandrov ${ }^{\mathrm{b}}$ and Sergey F. Ordon ${ }^{\mathrm{c}}$ \\ "RUSAL ETC" Kamensk-Uralsk \\ 4 Zavodskaya Str., Kamensk-Uralsky, 623406, Russia \\ ${ }^{b}$ Department of Technology and Technical Development \\ of Alumina Production, Separate Division Achinsk \\ 1 bld., XII quarter, South industrial zone, Achinsk, 662153, Russia \\ "RUSAL ETC" \\ 86 Sredniy, Saint-Petersburg, 199106, Russia
}

The existing experience of the alumina refineries Warehousing red mud formed by the hydrochemical processing of raw material bauxite. A comparative evaluation of the application of different methods of dehydration of red mud for the purpose. The results on the use of the technology on a commercial scale ultra dry red mud storage.

Keywords: red mud, clay, bauxite, ultra-dry storage, filtering.

Citation: Gorbachev S.N., Alexandrov A.V., Ordon S.F. Prospects for the introduction of technology ultra-dry storage of red mud, J. Sib. Fed. Univ. Eng. technol., 2017, 10(7), 854-861. DOI: 10.17516/1999-494X-2017-10-7-854-861.

(C) Siberian Federal University. All rights reserved

* Corresponding author E-mail address: Sergey.Gorbachev3@rusal.com 


\title{
Перспективы внедрения технологии
}

\section{ультрасухого складирования красного шлама}

\author{
С.Н. Горбачев ${ }^{\text {, }}$ \\ А.В. Александров ${ }^{\boldsymbol{0}}$, С.Ф. Ордон \\ "ООО “РУСАЛ ИТЦ” Каменск-Уральск \\ Россия, 623406, Каменск-Уральский, ул. Заводская, 4 \\ ${ }^{6}$ Департамент по технологии и техническому развитию \\ глиноземного производства, обособленное подразделение г. Ачинск \\ Россия, 662153, Ачинск, Южная промзона, квартал XII, стр. 1 \\ ${ }^{\circ} О О О$ «РУСАЛ ИТЦ» \\ Россия, 199106, Санкт-Петербург, Средний пр., 86
}

\begin{abstract}
Рассмотрен существующий опыт глинозёмных заводов по складированию красных иламов, образующихся пригидрохимической переработке бокситового сырья. Проведена сравнительная оиенка применения различных способов обезвоживания красного шлама. Представлены результаты по использованию в промышленном масштабе технологии ультрасухого складирования красного шлама.
\end{abstract}

Ключевые слова: красный шлам, глинозем, бокситы, ультрасухое складирование, фильтрация.

\section{Введение}

В настоящее время при переработке боксита на глинозем его подвергают прямому выщелачиванию (способ Байера) либо выщелачивание боксита сочетают с высокотемпературным спеканием (параллельно комбинированный и последовательно комбинированный способы Байер-спекания). Отходами переработки бокситов являются так называемые красные шламы.

Красные шламы - многотоннажный отход глинозёмного производства, общий годовой выход красных шламов на заводах ОК РУСАЛ превышает 6,5 млн т, поэтому их утилизация считается одной из приоритетных задач. Шламохранилища служат источником загрязнения окружающей среды (в том числе и за счет риска прорыва шламохранилищ), а земли на устройство шламохранилищ выводятся из полезного землепользования.

В данной статье мы затронем в основном вопросы, связанные с технологией транспортировки и складирования красных шламов в мировой практике и в России.

\section{Технология складирования красного шлама на глинозёмных заводах}

Доставка шламов из производства до шламохранилищ на всех глинозёмных заводах ОК РУСАЛ осуществляется гидротранспортом с последующим возвратом осветленной подшламовой воды. Размещение шламохранилищ определяется местными условиями, расстояние их от заводов неодинаково и составляет от 1,5 до 9 км. Площади шламохранилищ в зависимости от годового выхода шламов, проектной высоты и проектного срока службы, а также способа возведения насчитывают от 70 до 250 га. На шламохранилищах, возводимых намывом, ограждающие дамбы формируются из складируемых шламов (АГК, карта № 1 шламохранилища 
№ 2 БАЗ). Шламохранилища, полезная емкость которых образована дамбами, отсыпанными из местных грунтов, заполняются байеровскими шламами наливом (Aughinish, Ewarton, НГЗ, УАЗ, карта № 2 шламохранилище № 2 БАЗ). Подача шламов на шламохранилища производится непрерывно круглый год [1].

Шламохранилища являются неотъемлемым звеном непрерывного процесса производства глинозема, и роль их в обеспечении нормального производственного процесса не менее важна, чем любого другого передела. Поэтому вопросы экономичности и надежности работы шламохранилищ имеют первостепенное значение.

Из технологического процесса после последних ступеней промывки шламы подаются в шламбассейны шламонасосных станций по лоткам или напорным трубопроводам влажными или в виде пульпы с отношением твердого к жидкому по массе т:ж $=1: 2,5$ с температурой 70-98 ${ }^{\circ} \mathrm{C}$. В шламобассейнах красные шламы репульпируются водой с перемешиванием мешалками до транспортабельного т:ж = 1:5 и менее и грунтовыми или песковыми насосами перекачиваются на шламохранилища. В случае применения технологии удаления шлама высокой плотности (т:ж = 1:1) используют мембранные насосы (НГЗ). Каких-либо буферных емкостей для шлама на заводах не предусматривается, и система шламоудаления работает как конечная стадия непрерывного технологического процесса производства глинозема.

Для обеспечения надежности предусматривается резервирование насосов и трубопроводов. Таким образом обеспечивается их надежная работа. Вода на репульпацию шлама подается оборотная, возвращаемая со шламохранилища.

Температура шламовой пульпы на выходе обычно составляет $40-60{ }^{\circ} \mathrm{C}$ в зависимости от степени разбавления пульпы и сезонной температуры возвращаемой оборотной воды. От насосной станции шламовая пульпа перекачивается с помощью последующих шламонасосных станций по магистральным шламопроводам до шламохранилища и далее через выпуски разводящего шламопровода подается в чашу шламохранилища.

Для перекачки разбавленной пульпы (т:ж = 1:3-5) применяют грунтовые и песковые насосы марок ГР и ПС, развивающие напоры 60-90 м, для перекачки технологии удаления шлама высокой плотности (т:ж = 1:1) - мембранные насосы (НГЗ). Для шламопроводов применяются стальные либо полимерные трубы. По территории завода шламопровода прокладывают, как правило, на высоких эстакадах, а вне заводской площадки - на эстакадах или низких бетонных опорах. Разводящие шламопровода укладывают на низких постоянных или передвижных опорах. Для снятия температурных напряжений на магистральных шламопроводах предусматриваются компенсирующие устройства. Шламопроводы прокладывают с уклоном, чтобы при прекращении подачи шлама их можно было опорожнить, слив пульпу. Перед участками подъема оборудуются выпуски для сброса пульпы в емкости аварийного слива.

Гранулометрический состав шлама в пульпе зависит от характеристик бокситов, способа и особенностей технологического процесса производства глинозема (табл. 1).

Крупные частицы спекательных шламов, имеющие острые грани и обладающие абразивными свойствами, вызывают интенсивное истирание шламопроводов, особенно на поворотах (ПАЗ и БГЗ). Интенсивно истираются рабочие колеса и проточная часть грунтовых насосов, отчего уменьшаются напоры и к.п.д. и требуется периодическая замена колес и рабочих камер насосов. 


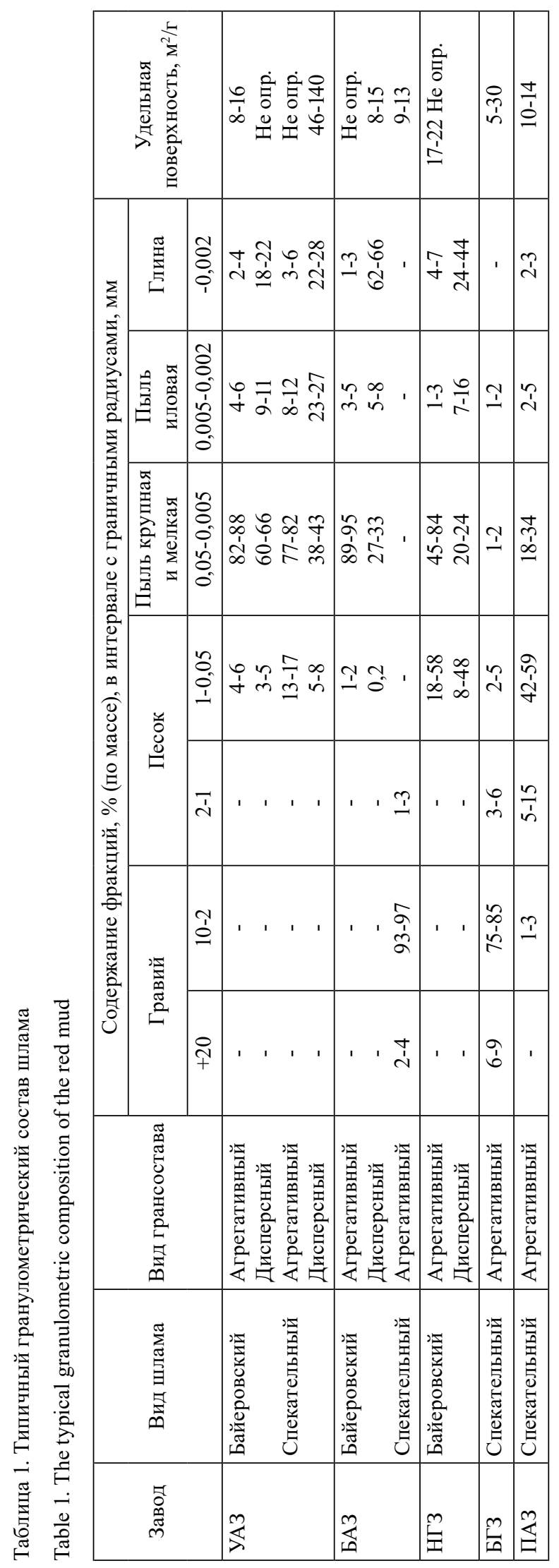


Система гидротранспорта шламов работает в двух режимах - установившемся и неустановившемся. Установившийся режим характеризуется постоянством напора и расхода. Неустановившийся режим возникает при маневрировании задвижками и насосами, что при резком изменении действующих напоров и скоростей в шламопроводах с соответствующим изменением расхода пульпы может вызвать гидравлический удар, проявляющийся волновым понижением или многократным повышением давления в трубопроводах и приводящий иногда к разрушению шламопровода. Для предотвращения гидроудара, самый опасный из которых сопровождается соударением масс пульпы при ликвидации вакуума, возникшего после разрыва сплошности потока, на опасных участках шламопроводов устанавливают специальную арматуру типа клапанов для впуска воды или воздуха либо гасители других конструкций [1].

Ныне действующие системы гидротранспорта нельзя признать достаточно высокоэффективными, так как для транспортирования шлама приходится перекачивать на шламохранилище и обратно массу воды, в 10-20 раз большую, чем масса шлама. Для этого требуются мощные насосы, шламопровода и водоводы больших диаметров и система возврата осветленной воды, а также большие затраты электроэнергии.

Кроме того, в порах шламовых отложений теряется алюминат натрия. Шламохранилища при этом возводятся большого объема, с дорогими противофильтрационными экранами и сложные в эксплуатации. Затруднена и отгрузка шламов из водонасыщенных шламовых отложений потребителям [2].

Транспортирование сгущенных шламов позволяет отказаться от системы возврата подшламовых вод и приводит к резкому сокращению капитальных и эксплуатационных затрат на системах шламоудаления, делает их менее вредными для окружающей среды. Байеровские шламы поддаются перекачке при влажности 50 \% за счет своей тиксотропности, а при больших расстояниях - с помощью пластификаторов. Возможна также перекачка сгущенных смешанных и спекательных шламов. Технология транспортирования шламов высокой плотности реализована на НГЗ, что позволяет перекачивать шламы с т:ж = 1:1.

\section{Преимущества ультрасухого складирования}

Важное место в технологии утилизации и возможной переработки красного шлама занимает операция обезвоживания, которая обеспечивает не только эффективное складирование шлама, но и его отгрузку потребителю, а также подготовку к последующим процессам переработки. Можно выделить несколько способов обезвоживания шлама, которые имеют различную степень применимости в связи с дальнейшим направлением его переработки (рис. 1) [3].

Очевидно, что для шламов, выходящих из системы сгущения и промывки глиноземных заводов с (т:ж) $=(2,5-3,5): 1$, нецелесообразно применение операции тепловой или химической сушки из-за большого расхода топлива или связывающего влагу вещества.

Наиболее универсальным является способ фильтрования, который благодаря возможностям современного оборудования позволяет получать шламы с низкой влажностью. В настоящее время в мировой практике данная технология называется ультрасухим складированием (Dry Disposal). Данная технология предусматривает получение кека красного шлама на прессфильтре или гипербарическом фильтре с влажностью 23-30 \%. Доставка на шламовое поле осу- 


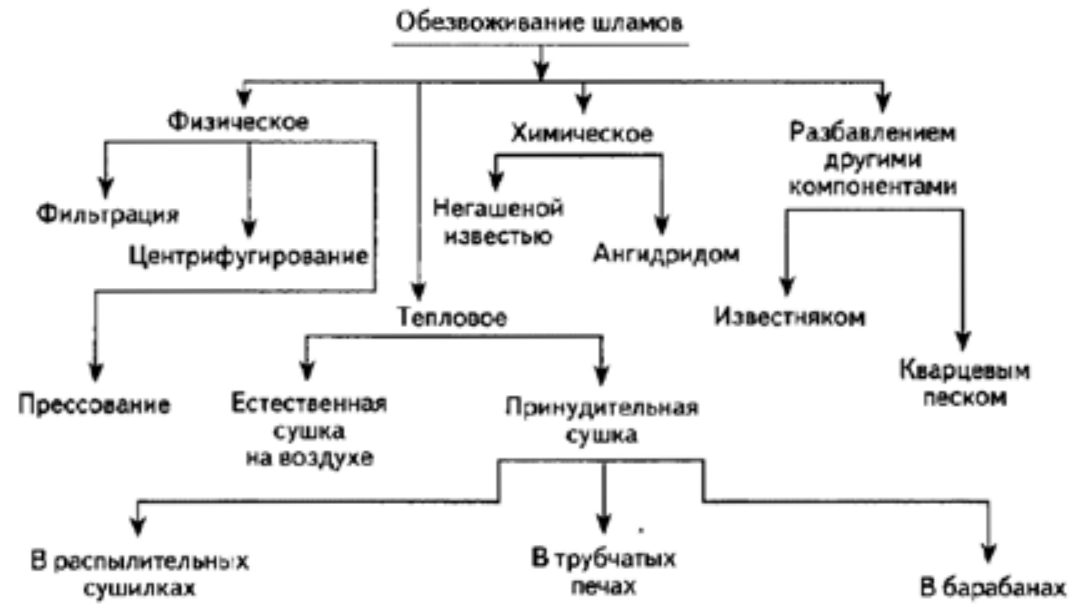

Рис. 1. Способы обезвоживания красных шламов

Fig. 1. Methods of dewatering of red mud
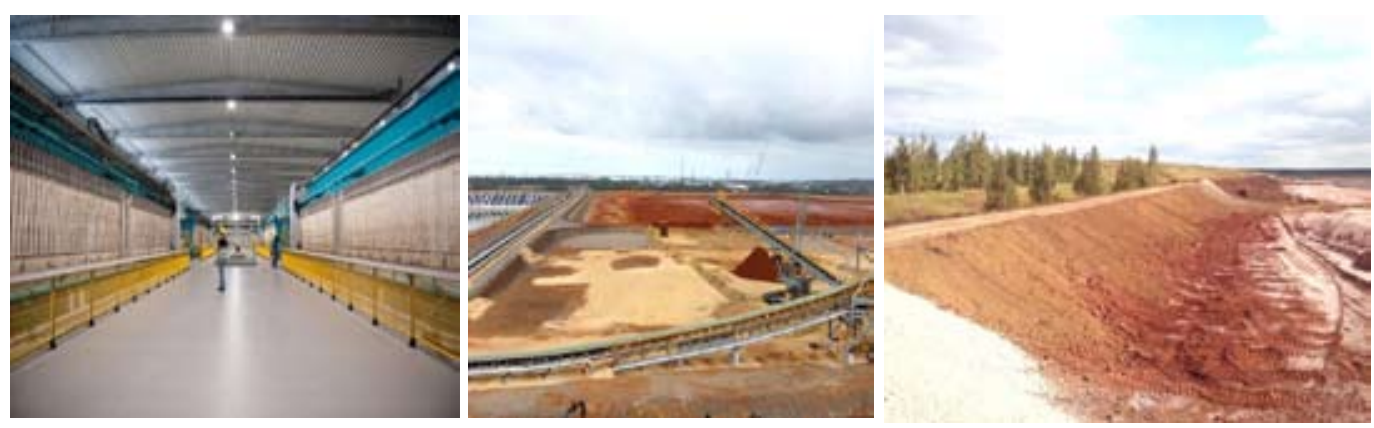

Рис. 2. Исполнение технологии ультрасухого складирования

Fig. 2. Performance of technology ultradry storage

ществляется грузовиками или конвейерами различного типа. Шлам складируется в виде штабеля или карты сыпучего материала и формируется экскаваторной и бульдозерной техникой.

С 2010 г. данная технология широко используется при строительстве новых заводов в Китае и других странах (рис. 2).

Например, эта технология внедряется на заводах Бразилии. Так, завод Alunorte, самый крупный завод по производству глинозема (Бразилия, г. Баркарена) - производительность 6,3 млн т $\mathrm{Al}_{2} \mathrm{O}_{3}$ в год, полностью перешел на ультрасухое складирование, весь шлам отжимается на пресс-фильтрах нового поколения Outotec $(7+1)$ до влажности $22 \%$. Шлам к месту складирования перевозится 40-тонными грузовиками (60\%), остальной объем (40 \%) - конвейером закрытого типа. Внедрение новой технологии складирования позволит продлить срок службы шламполя с 2019 г. до 2050 г. без использования новых земель под складирование. В качестве альтернативы пресс-фильтрам в первом квартале 2015 г. совместно с компанией Alfa Laval на заводе провели испытания по разделению нижнего слива промывателей последней стадии с применением декантерной центрифуги. Результаты испытаний с использованием синтетиче- 
Таблица 2. Сравнительные данные по различным способам складирования красного шлама

Table 2. Comparative data on the various methods of storage of red mud

\begin{tabular}{|c|c|c|c|}
\hline Параметры & Ед. изм. & $\begin{array}{l}\text { Вариант сухого } \\
\text { складирования }\end{array}$ & Гидронамыв \\
\hline $\begin{array}{l}\text { Площадь шламохранилища № } 4 \text { в осях гребня } \\
\text { ограждающей дамбы }\end{array}$ & га & 296 & 296 \\
\hline $\begin{array}{l}\text { Максимальная высота низового откоса ограждающей } \\
\text { дамбы }\end{array}$ & M & 5 & 14,5 \\
\hline Высота шламового массива & M & 100 & 14 \\
\hline \multirow{2}{*}{ Вместимость шламохранилища } & тыс. $\mathrm{M}^{3}$ & 181730 & 32300 \\
\hline & тыс. т & 352556 & 58140 \\
\hline Затраты на подготовку шламонакопителя к работе & тыс. руб. & 3566194,75 & 5678574,34 \\
\hline \multirow{2}{*}{$\begin{array}{l}\text { Удельные капитальные затраты на складирование } \\
1 \text { т шлама (без учета стоимости станции фильтрации } \\
\text { шлама, оборудования для транспортировки и } \\
\text { складирования шлама) }\end{array}$} & тыс. руб/м ${ }^{3}$ & 19,623 & 175,807 \\
\hline & тыс. руб/т & 10,115 & 97,67 \\
\hline
\end{tabular}

ского флокулянта показали сухость осадка после обработки на уровне 67-69 \% при очень хорошем уровне осветления (99\%).

В России в период 2015-2016 гг. специалистами РУСАЛ ИТЦ и СибВАМИ проведен комплекс исследовательских работ и выполнен сравнительный анализ двух способов складирования шлама УАЗа - сухое складирование фильтрованного кека красного шлама и используемое в настоящее время складирование с помощью гидротранспорта (гидронамыв). Сравнение показателей при различных способов складирования красного шлама приведено в табл. 2.

Применительно к УАЗу выделим основные преимущества технологии:

- на одинаковой площади вместимость шламоотвала в 6 раз выше;

- затраты на подготовку шламонакопителя к работе в 1,6 раза ниже;

- удельные капитальные затраты на складирование 1 т шлама в 9,7 раза ниже;

- исключаются требования к гидротехническим сооружениям и вытекающие из этого обязательства.

В настоящее время проведен комплекс лабораторных работ по изучению свойств отфильтрованного красного шлама УАЗ. Разработаны основные технические решения по его складированию. Планируется создание опытной ячейки шламового поля на УАЗе для отработки технологии и определения операционных затрат.

\section{Заключение}

Существующее оборудование (пресс-фильтры, декантерные центрифуги) обеспечивают остаточную влажность шлама, пригодную для ультрасухого складирования.

Ультрасухое складирование внедрено в промышленных масштабах на ряде глиноземных заводов мира.

Наиболее целесообразным внедрение технологии ультрасухого складирования из-за дополнительных по сравнению с наливным способом капитальных и эксплуатационных затрат 
на узел фильтрации может быть при строительстве нового шламоотвала или при использовании имеющегося оборудования и инфраструктуры фильтрации.

Нужно создать на шламохранилище УАЗа опытный участок для отработки технологии ультрасухого складирования и организации опытно-промышленного полигона с использованием фильтрационной установки опытного участка производства скандиевого концентрата.

\section{Список литературы}

[1] Корнеев В.И., Сусс А.Г., Цеховой А.И. Красные шламы - свойства, складирование, применение. М.: Металлургия, 1991. 144 с. [Korneev V.I., Suss A.G., Tsehovoi A.I. Red mud - properties, storage, application. Moscow, Metallurgia, 1991, 144 p. (in Russian)]

[2] Утков В.А., Яковлев М.Г. Промышленный опыт подготовки и агломерации бокситового красного шлама. Цветные металль, 2013, 3, 46-48 [Utkov V.A., Yakovlev M.G. Industrial experience of the preparation and agglomeration of red bauxite mud. Nonferrous metals, 2013, 3, 46-48 (in Russian)]

[3] Бричкин В.Н., Дубовиков О.А., Николаева Н.В., Беседин А.А. Обезвоживание красного шлама и основные направления его переработки. Обогащение руд, 2014, 1, 44-48 [Brichkin V.N., Dubovikov O.A., Nikolayeva N.V., Besedin A.A. Red mud dewatering and basic trends in its recycling. Beneficiation of ores, 2014, 1, 44-48 (in Russian)] 